\title{
MODELS FOR PROFILE CHANGE OF RUBBLE MOUND REVETMENT AND PERFORMANCE EVALUATION
}

\author{
Takao Ota ${ }^{1}$, Yoshiharu Matsumi ${ }^{2}$, Takayuki Hirayama ${ }^{3}$ and Akira Kimura ${ }^{4}$
}

\begin{abstract}
This study deals with modeling for profile change due to damage progression of rubble mound revetment. The model profiles based on the experimental results consist of three datum points and two sine curves corresponding to the degree of deformation of the revetment. The model profiles agree well with the measured profiles. The model profiles are also used in other experiments and a time-averaged numerical model to examine the change of performance due to damage progression. The reflection coefficient and overtopping rate are taken as performance indices. The measured reflection coefficient decreases slightly, but the overtopping rate increases with damage progression of the revetment. The computed reflection coefficient is almost constant and the overtopping rate shows opposite tendency to the experimental result.
\end{abstract}

Keywords: rubble mound revetment; profile change; damage progression; performance evaluation

\section{INTRODUCTION}

The performance-based design of coastal structures is recently becoming standard. In this design, it is necessary to satisfy the performance required for structure and to consider the performance retention during the lifetime. The maintenance of coastal structures is important because the structures are generally placed under severe environmental conditions and have a high probability of performance degradation due to damage progression during the lifetime. To perform appropriate maintenance of the structures, the quantitative evaluation of the degree of performance degradation induced by damage progression will be needed. The qualitative relation between the change of performance and the damage of structure has been investigated about armor layer of seawall or breakwater mainly by laboratory experiments (e.g., Kajima et al., 1993; Ota et al., 2007); however, the quantitative relation is not clarified. One of the reasons is that the process of profile change is different in each experiment. In this study, an attempt to make model for profile change of rubble mound revetment is made based on experimental data. Then the performance evaluation is conducted based on laboratory experiments and numerical computation using the model profile. The reflection coefficient and overtopping rate are taken as performance indices and used to assess the influence of damage progression on the performance.

\section{EXPERIMENTS TO MEASURE PROFILE CHANGE}

Laboratory experiments to obtain data of profile change were conducted in a wave flume that was $29 \mathrm{~m}$ long, $0.5 \mathrm{~m}$ wide and $0.75 \mathrm{~m}$ high. A conventional rubble mound revetment was constructed on the flat bottom of the wave flume. The crest width and height were $10 \mathrm{~cm}$ and $15 \mathrm{~cm}$. The initial seaward slope of the revetment was 1:1.5 for Case 1 and 1:2 for Case 2. The revetment consisted of a core and an armor layer whose vertical thickness was about $15 \mathrm{~cm}$. The experimental setup is shown in

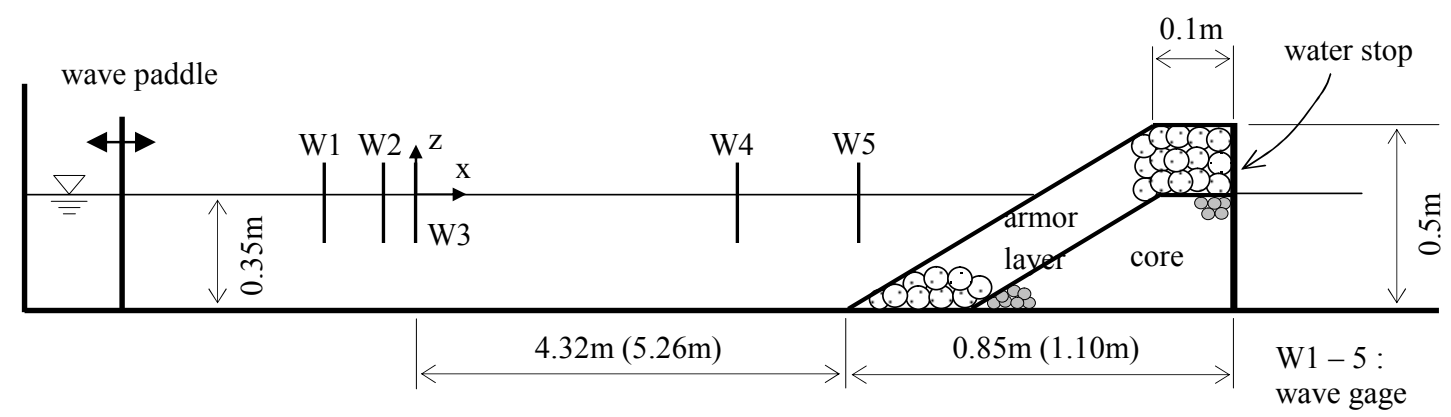

Figure 1. Experimental setup

\footnotetext{
${ }^{1}$ Dept. of Social Systems Eng., Tottori University, 4-101 Koyama Minami, Tottori, 680-8552, Japan

2 Dept. of Social Systems Eng., Tottori University, 4-101 Koyama Minami, Tottori, 680-8552, Japan

${ }_{3}^{3}$ Kyusyu Branch, Sansyosuiko Inc., 3-3-3 Hakataeki Higashi Hakata, Fukuoka, 812-0013, Japan

${ }^{4}$ Professor emeritus, Tottori University, 4-101 Koyama Minami, Tottori, 680-8552, Japan
} 
Figure 1, and the values in the parenthesis correspond to Case 2. The median mass, mean density and nominal diameter of the armor stone were $M_{50}=41.1 \mathrm{~g}, \rho_{s}=2.58 \mathrm{~g} / \mathrm{cm}^{3}$ and $D_{n 50}=2.52 \mathrm{~cm}$ respectively. The mass of all stones was in the range of $35-50 \mathrm{~g}$. The porosity of the armor stone was about 0.4 . The JONSWAP spectrum with the shape parameter $\gamma=3.3$ and significant wave period $T_{1 / 3}=1.6 \mathrm{~s}$ was used as the target spectrum of the incident irregular wave. The waves were generated in bursts of $20 \mathrm{~min}$ repeatedly until the damage extended to the upper part of the seaward slope. The significant wave height $H_{1 / 3}$ was $10.5 \mathrm{~cm}$ for Case 1 and $10.0 \mathrm{~cm}$ for Case2. Five wave gages were placed to measure the time series of the free surface elevations. Wave gages W1 - W3 were used to separate the incident and reflected waves using linear wave theory. The cross-shore coordinate $x$ is positive onshore with $x=0$ at wave gage W3 and the vertical coordinate $z$ is taken to be positive upward with $z=0$ at the still water level. The measurement was started after $20 \mathrm{~s}$ into the wave generation and 1150-second time series were collected at a sampling rate of $20 \mathrm{~Hz}$. The profiles of the revetment were measured every $20 \mathrm{~min}$ along five cross-shore lines using a laser displacement sensor. The profile of the revetment was given as the average of the profiles measured along five lines. Four tests (test1-4) were conducted for Case 1 and 2 respectively.

\section{EXPERIMENTAL RESULTS AND MODELING FOR PROFILE CHANGE}

Figure 2 shows the profile evolution of the seaward slope of the revetment measured in Case 1 and 2. The damage occurred around the still water level and the dislodged stones deposited on the lower part of the slope. The eroded area $A_{e}$ is calculated using the damaged and initial (undamaged) profiles.

Figures 3 and 4 show the corresponding temporal variations of the normalized eroded area $S=A_{e} / D_{n 50}^{2}$ and the reflection coefficient $K_{R}=H_{m 0 r} / H_{m 0 i}$ with $H_{m 0 r}$ and $H_{m 0 i}=$ reflected and incident spectral significant wave height in Case 1. $S$ increased with the cumulative number of waves $N_{w}$; however, $K_{R}$ decreased slightly with damage progression of the revetment. The variations of $K_{R}$ were in the range of $0.06-0.09$ for Case 1 and $0.03-0.06$ for Case 2 .

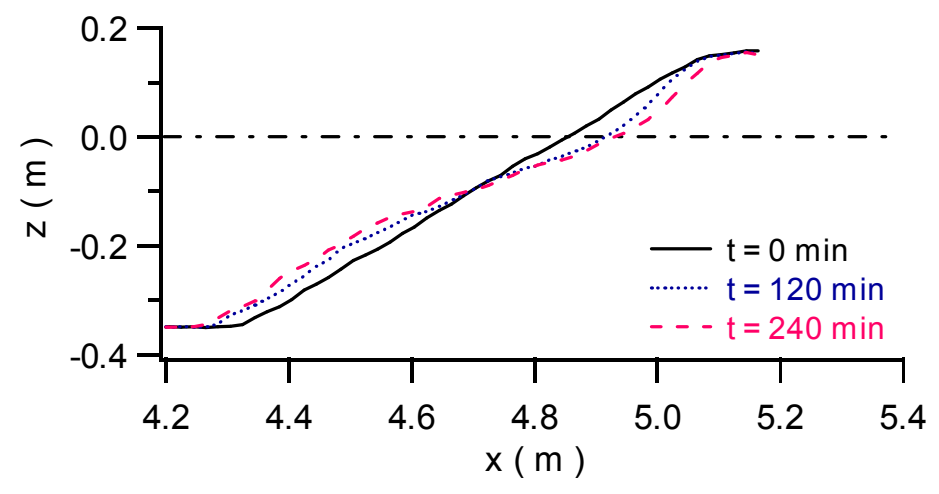

(a) Case 1

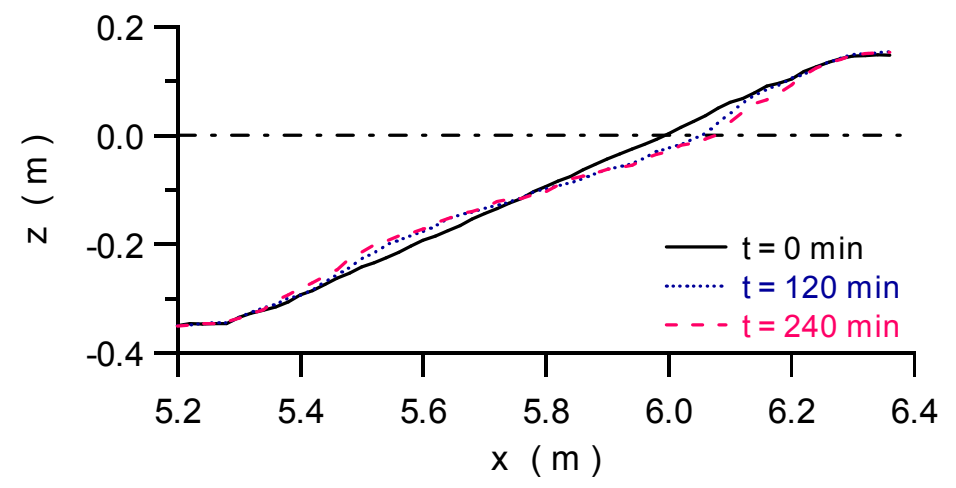

(b) Case 2

Figure 2. Profile evolution 
As shown in Figure 3, the processes of the profile change were different in each test though the experiments were conducted under the same conditions. Ota et al. (2009) pointed out that the overtopping quantity was especially affected by the difference of the profile change and the experimental results varied. Moreover, even if the values of $S$ are the same, the profiles do not agree completely including the local irregularities. Therefore, it is considered that many experimental data are necessary for clarifying the quantitative relation between the profile change and overtopping quantity. On the other hand, if an average (standard) profile can be determined corresponding to $S$, it might be useful for the quantitative evaluation of the performance.

Figure 5 shows the measured profile evolution in a test. The intersections of the initial profile and damaged profiles (Point $\mathrm{C}$ in Figure 5) were almost constant in spite of the damage progression. Three

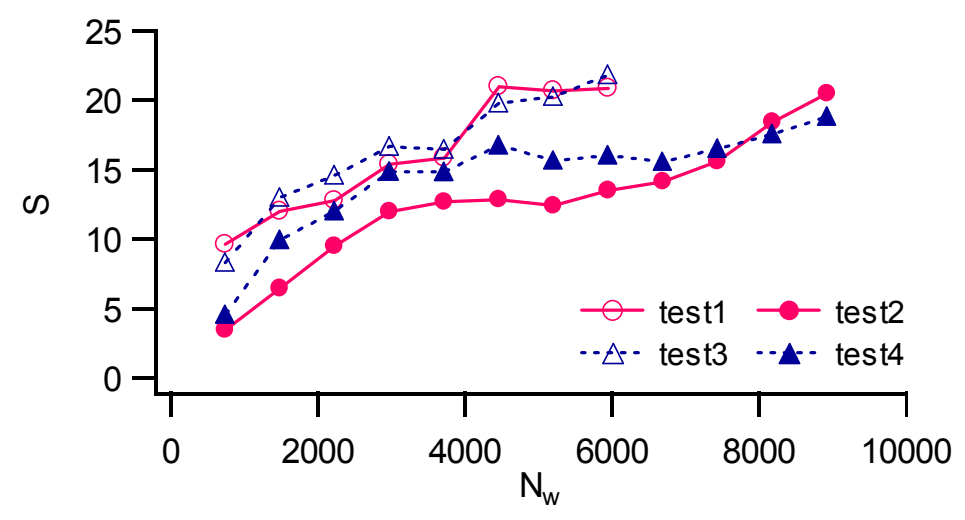

Figure 3. Variation of normalized eroded area (Case 1)

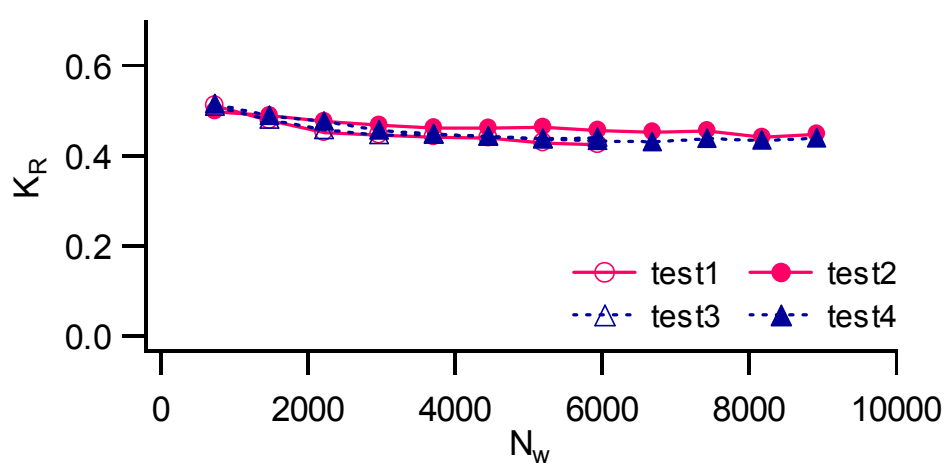

Figure 4. Variation of reflection coefficient (Case 1)

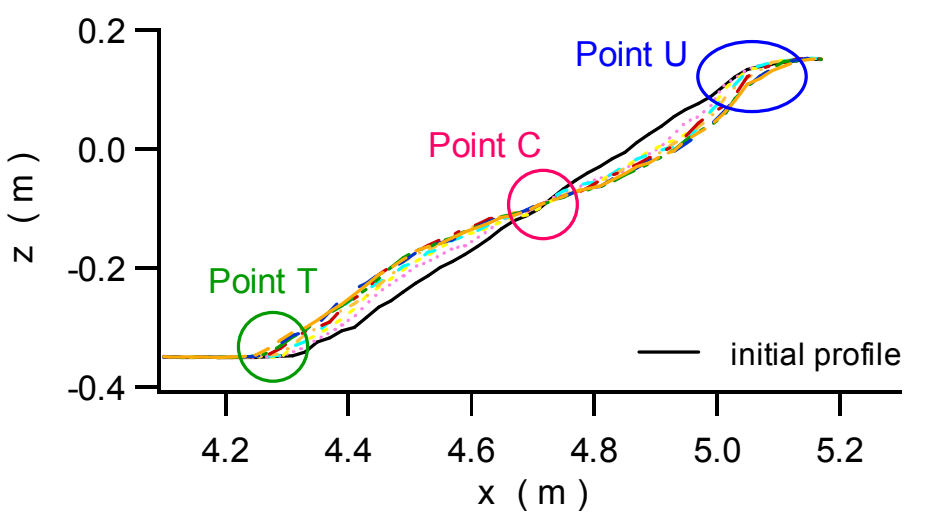

Figure 5. Datum points 
points including the toe of the revetment (Point $\mathrm{T}$ ) and the upper end of the eroded area (Point $\mathrm{U}$ ) are treated as the datum points. For the modeling of the profile, it is necessary to determine the position of the datum points and the curves connecting the points. In this study, we attempt to approximate the profiles of the eroded and deposited region by two sine curves.

The $x$-coordinate of Point T, the $x$ and $z$-coordinate of Point $\mathrm{C}$ and $\mathrm{U}$ can be read from the each measured profile. The position of Point $\mathrm{C}$ is determined by the average of the obtained $x$-coordinate $\overline{x_{c}}$ and the $z$-coordinate corresponding to $\overline{x_{c}}$ on the initial model profile shown in Figure 1. As the results, the positions are $(4.72,-0.083)$ for Case 1 and $(5.75,-0.105)$ for Case 2 . Figure 6 shows the relation between $S$ and the $x$-coordinate of Point $\mathrm{U} x_{U}$. The regression lines and expressions obtained by the method of least squares are also shown in the figures. The relations between $S$ and the $z$-coordinate of Point $U z_{U}$ are also obtained; however, only $x_{U}$ is given by the empirical equation shown in the figures. Consequently, the value of $z_{U}$ is determined as the $z$-coordinate corresponding to $x_{U}$ on the initial model profile. The reason is that the $x$ and $z$-coordinate of Point $\mathrm{U}$ given by the respective empirical equations are not always on the initial model profile due to the experimental errors. As for the $x$-coordinate of Point T $x_{T}$, the relations with $S$ are also obtained; however, Point $\mathrm{T}$ is fixed at the position on the initial model profile so as to simplify the approximation of the profile by using sine curve.

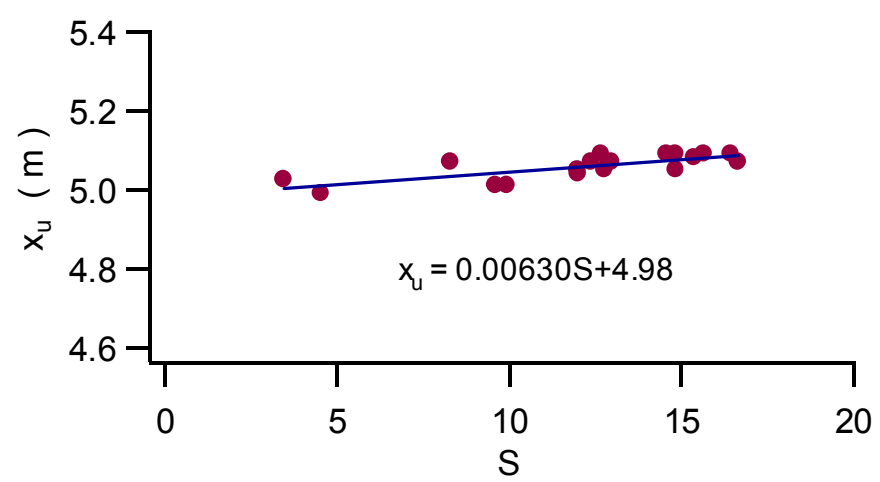

(a) Case 1

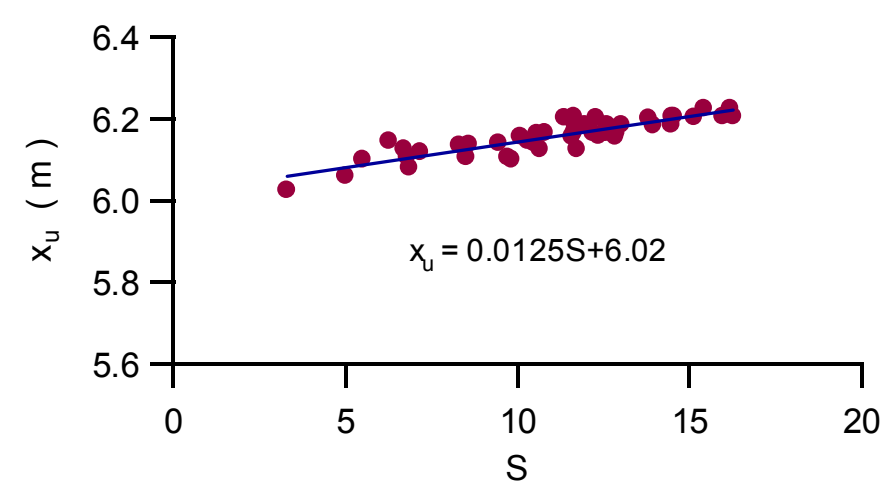

(b) Case 2

Figure 6. Relation between $S$ and $x_{U}$

The positions of Point $\mathrm{C}, \mathrm{U}$ and $\mathrm{T}$ are determined by the above-mentioned procedure. The model profiles are made by connecting the datum points with two sine curves whose half wavelengths are the same as the distances between the points. The amplitudes of sine curves are given so that the area bounded by the sine curve and the initial model profile is equal to the eroded area corresponding to the value of $S$. The amplitude of sine curve $a$ is obtained using $D_{n 50}=0.0252 \mathrm{~m}$ as

$$
a=\frac{6.35 \times 10^{-4} \pi S}{L}
$$




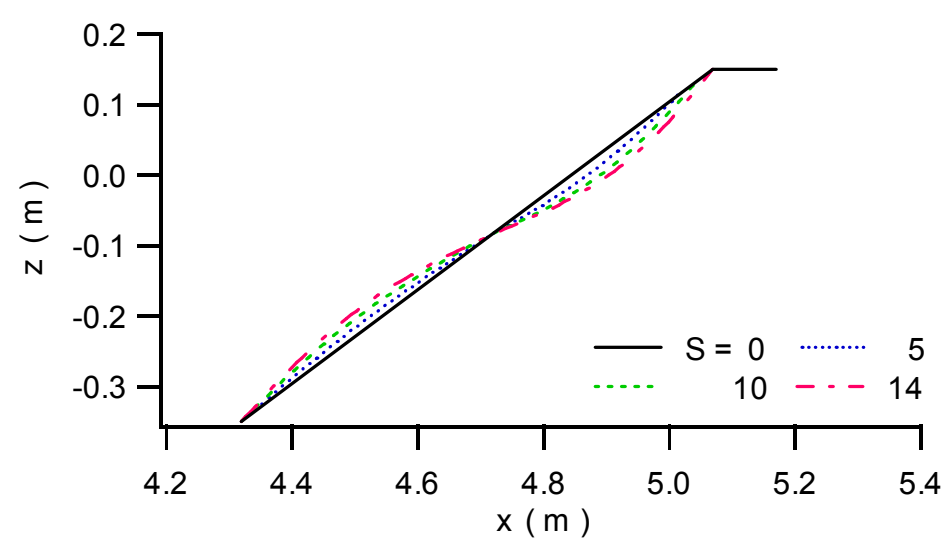

(a) Case 1 (1:1.5 slope)

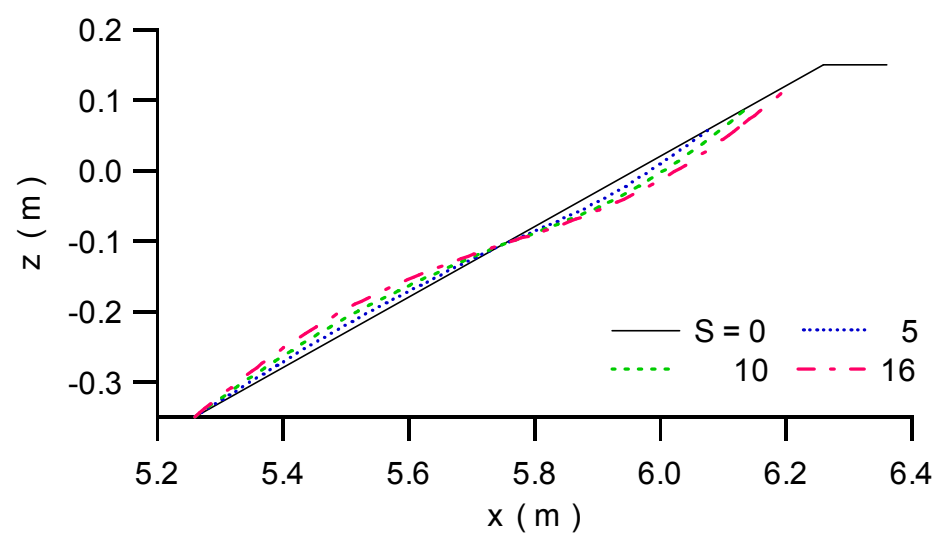

(b) Case 2 (1:2 slope)

Figure 7. Model profiles

where, $L=$ twice of the distance between two datum points. The model profiles in the case of $S=0$ (initial profile), 5, 10 and 14 for Case 1 (1:1.5 slope), and $S=0,5,10$ and 16 for Case 2 (1:2 slope) are shown in Figure 7. Figure 8 compares the model profiles in the cases of $S=14$ and 16 with the measured profiles whose values of $S$ are nearly equal in Case 1 and 2. The model profiles agree well with the experimental data.

\section{PERFORMANCE EVALUATION}

The experiments and computations using the model profiles are conducted to evaluate the performance of the damaged rubble mound revetment. The reflection coefficient and overtopping rate are taken as performance indices. In the experiments, the revetments which have the model profiles corresponding to $S=0,7,10$ and 14 for $1: 1.5$ slope, and $S=0,5,10$ and 16 for 1:2 slope respectively were set in the wave flume. The profile of each revetment was confirmed by the laser displacement sensor. The experimental setup was the same as shown in Figure 1. The crest and seaward slope of the revetment were covered by a wire sheet to fix the armor stone. The JONSWAP spectra with $\gamma=3.3$ and $T_{1 / 3}=1.2,1.3,1.4,1.6,1.8$ and $2.0 \mathrm{~s}$ were used as the target spectra of the incident irregular waves for the measurement of reflection coefficient. The waves were generated in bursts of $10 \mathrm{~min}$ and the significant wave height $H_{1 / 3}$ was about $8.5 \mathrm{~cm}$. The irregular wave used for Case 2 in the abovementioned experiments was generated for the measurement of overtopping quantity. A measuring box whose width was $37.5 \mathrm{~cm}$ was placed behind the water stop to collect the overtopped water.

In this study, the numerical model proposed by Kobayashi and de los Santos (2007) is used to estimate the reflection coefficient and overtopping rate. This model is based on the time-averaged wave propagation model and the probabilistic model for wave runup and overtopping. The wave propagation model is based on the time-averaged continuity, momentum and energy equations. The model predicts 


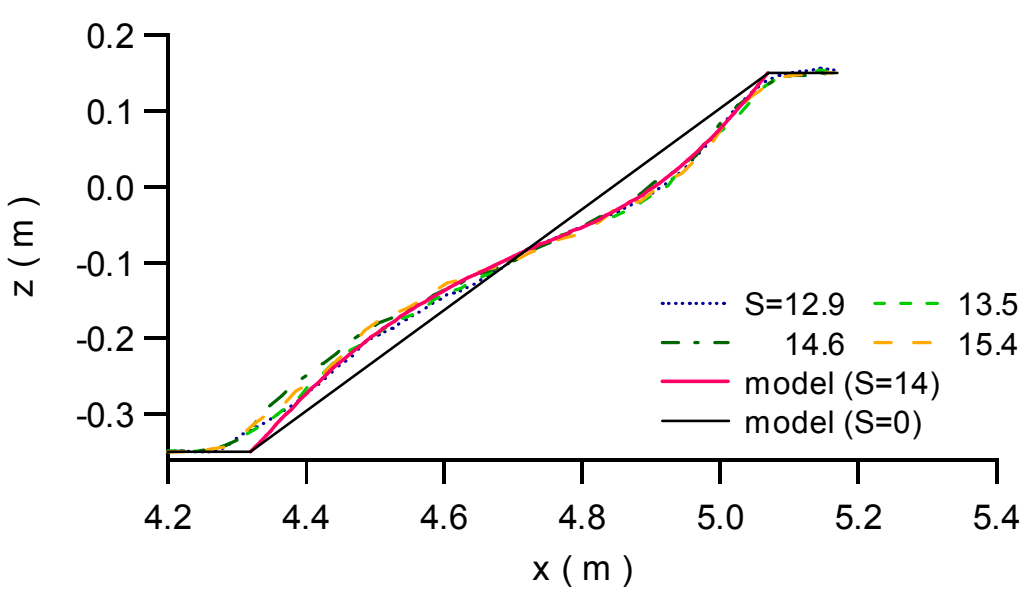

(a) 1:1.5 slope

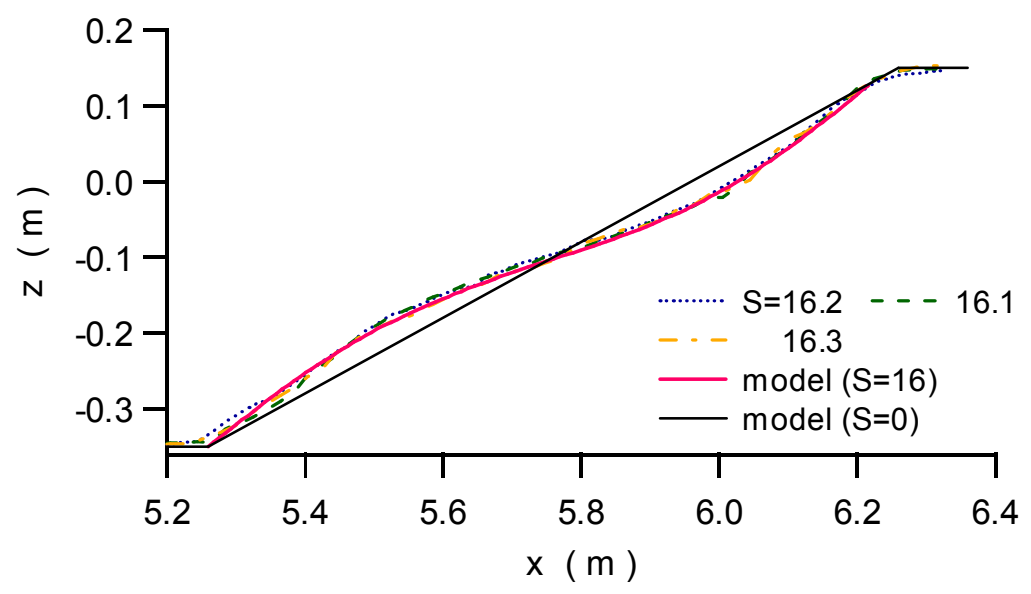

(b) 1:2 slope

Figure 8. Model and measured profiles

the cross-shore variations of the energy flux, energy dissipation rate, the mean and standard deviation of the free surface elevation and horizontal velocities above and inside a porous structure. This model does not contain the reflected wave; however, the degree of wave reflection is estimated assuming the residual energy flux at the still water shoreline is reflected and propagates seaward with group velocity. In the wave runup and overtopping model, the mean and standard deviation of the free surface elevation calculated by the wave propagation model are used to estimate them of the shoreline elevation on the seaward slope of the structure assuming a virtual runup wire is set above the slope. The significant runup height defined as the average of $1 / 3$ highest values of the runup height is given by using the predicted mean and standard deviation of the shoreline elevation. The overtopping rate is estimated by an empirical formula assuming the Weibull distribution for the probability distribution of the runup height. For further detail of the numerical model, Ota et al. (2007) can be also referred.

In the computations, the model profiles corresponding to $S=0,3,5,7,10,12$ and 14 for 1:1.5 slope, and $S=0,3,5,7,10,12,14$ and 16 for 1:2 slope are used. The input for the computation includes the mean of the free surface elevation $\bar{\eta}$, the root-mean-square wave height $H_{r m s}$ and spectral peak period $T_{p}$ at $x=0$. The input conditions are given as $\bar{\eta}=0, H_{r m s}=\sqrt{8} \sigma_{\eta}$ and $T_{p}=1.07 T_{1 / 3}$, where $\sigma_{\eta}=$ the standard deviation of the free surface elevation measured at wave gage W3. The values of the empirical parameters in the wave propagation model calibrated by Kobayashi et al. (2007) are used. A virtual elevation of the runup wire parallel to the seaward slope of the revetment is $1.5 \mathrm{~cm}$ for the computation of the overtopping rate $q_{o}$ to deal with the deformation of the revetment. 


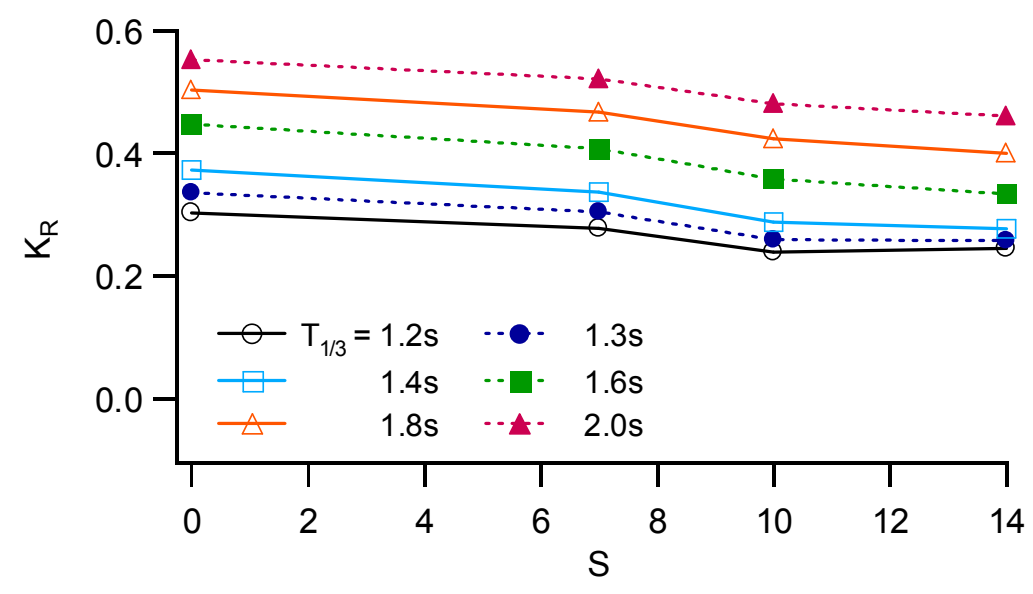

(a) 1:1.5 slope

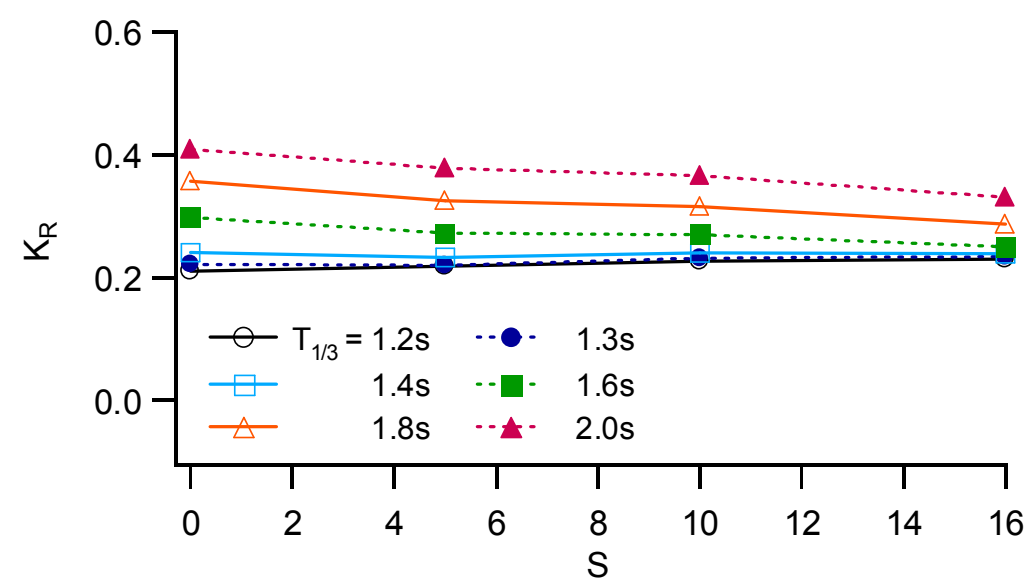

(b) 1:2 slope

Figure 9. Variation of measured reflection coefficient

Figure 9 shows the variations of the reflection coefficient $K_{R}$ obtained from the experiments using the model profiles. $K_{R}$ decreased with increasing $S$ except for the cases of the short-period waves on 1:2 slope. The variations of $K_{R}$ were in the range of $0.06-0.11$ for 1:1.5 slope and $0.05-0.08$ for 1:2 slope. In the cases of $T_{1 / 3}=1.2-1.4 \mathrm{~s}$ for 1:2 slope, $K_{R}$ increased only slightly or scarcely changed with $S$.

Figure 10 shows the comparisons of the measured $K_{R}$ and $q_{o}$ with the predicted values of them. The measured $K_{R}$ is obtained from the case of $T_{1 / 3}=1.6 \mathrm{~s}$, which is the same as shown in Figure 9 . The measured $K_{R}$ decreases with $S$ as mentioned above; however, the predicted $K_{R}$ does not change much. The measured $q_{o}$ increases with $S$ in whole. The ratios of $q_{o}$ at maximum $S$ to $S=0$ are about 1.9 for 1:1.5 slope and 1.8 for $1: 2$ slope. On the other hand, the predicted $q_{o}$ decreases with $S$. The numerical model predicts $q_{o}$ within about a factor of two; however, the predicted $q_{o}$ shows the opposite tendency to the experimental data.

Figure 11 shows the computed cross-shore variations of the wave energy flux $F^{*}=F /(\rho g)$ and the energy dissipation rate due to wave breaking $D_{B}{ }^{*}=D_{B} /(\rho g)$ for $1: 1.5$ slope, where $\rho=$ water density; g = gravitational acceleration. Linear wave theory is used to estimate $F$, and $D_{B}$ is calculated using the formula by Battjes and Stive (1985) which is modified by Kobayashi et al. (2007). The measured profile $(S=14.6)$ in Case 1 and the model profile corresponding to $S=14$ shown in Figure 8(a) are used. $F^{*}$ is normalized by $F^{*}$ at $x=0 . D_{B}{ }^{*}$ based on the measured profile fluctuates locally because of the irregularity of the profile. As shown in Figure 8(a), the model profile is somewhat different from the measured profiles in the lower part of the slope (about $4.3<x<4.5$ ). However, the difference of $F^{*}$ between the model and measured profile and the value of $D_{B}{ }^{*}$ are small in that region. This result 


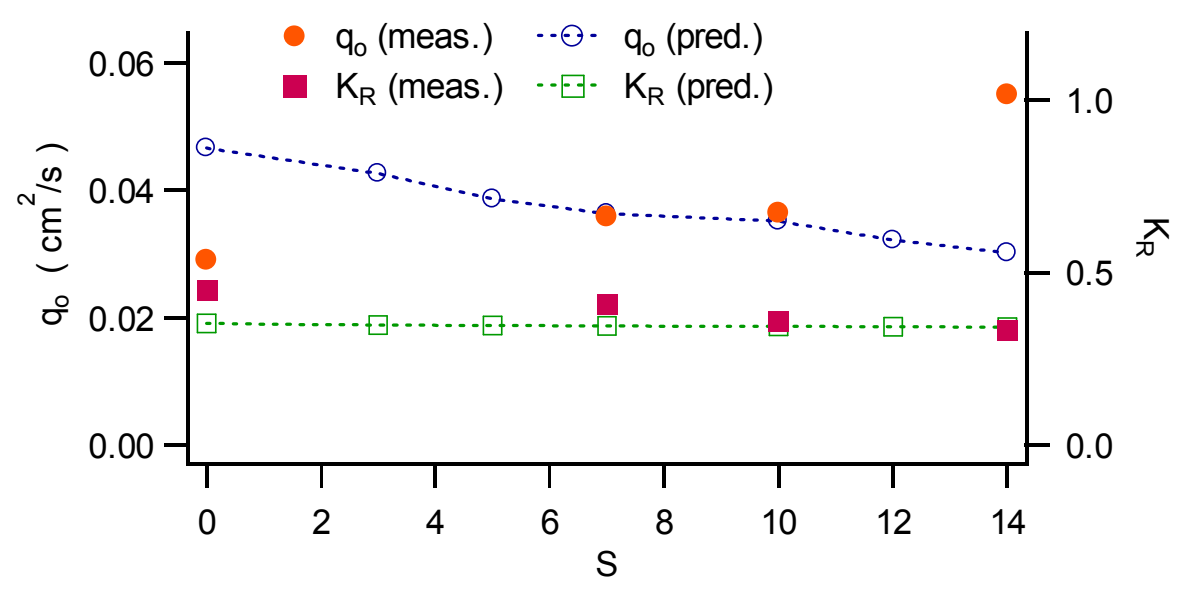

(a) 1:1.5 slope

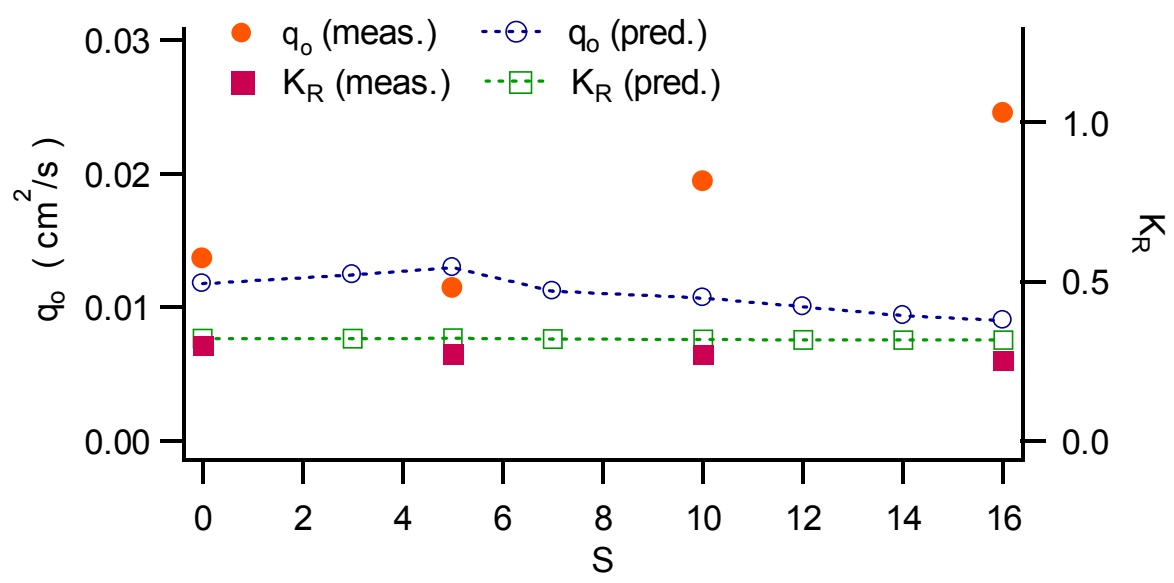

(b) 1:2 slope

Figure 10. Measured and predicted $K_{R}$ and $q_{0}$

indicates that the difference of the profile in the lower part of the slope does not influence much on wave.

\section{CONCLUSIONS}

A series of laboratory experiments were conducted in a wave flume to examine the profile change due to damage progression of rubble mound revetments with 1:1.5 and 1:2 seaward slopes. Based on the experimental data, the model profiles corresponding to the degree of damage progression are made. Furthermore, the experiments and computations using the model profiles are conducted to evaluate the performance of the damaged rubble mound revetment. The reflection coefficient and overtopping rate are taken as performance indices. The conclusions of this study are as follows;

1. The intersections of the initial profile and damaged profiles are almost constant in spite of the damage progression. This point, the toe of the revetment and the upper end of eroded area are taken as the datum points to make the model profile.

2. The model profiles corresponding to the normalized eroded area $S$ are obtained by using the position of the datum points and two sine curves. The model profiles agree well with the measured profiles.

3. The measured reflection coefficient $K_{R}$ obtained from the experiments using the model profiles decreases with increasing $S$ except for the cases of the short-period wave on 1:2 slope. The measured overtopping rate $q_{o}$ increases with $S$. The ratios of $q_{o}$ at maximum $S$ to $S=0$ are about 1.9 for $1: 1.5$ slope and 1.8 for $1: 2$ slope. 

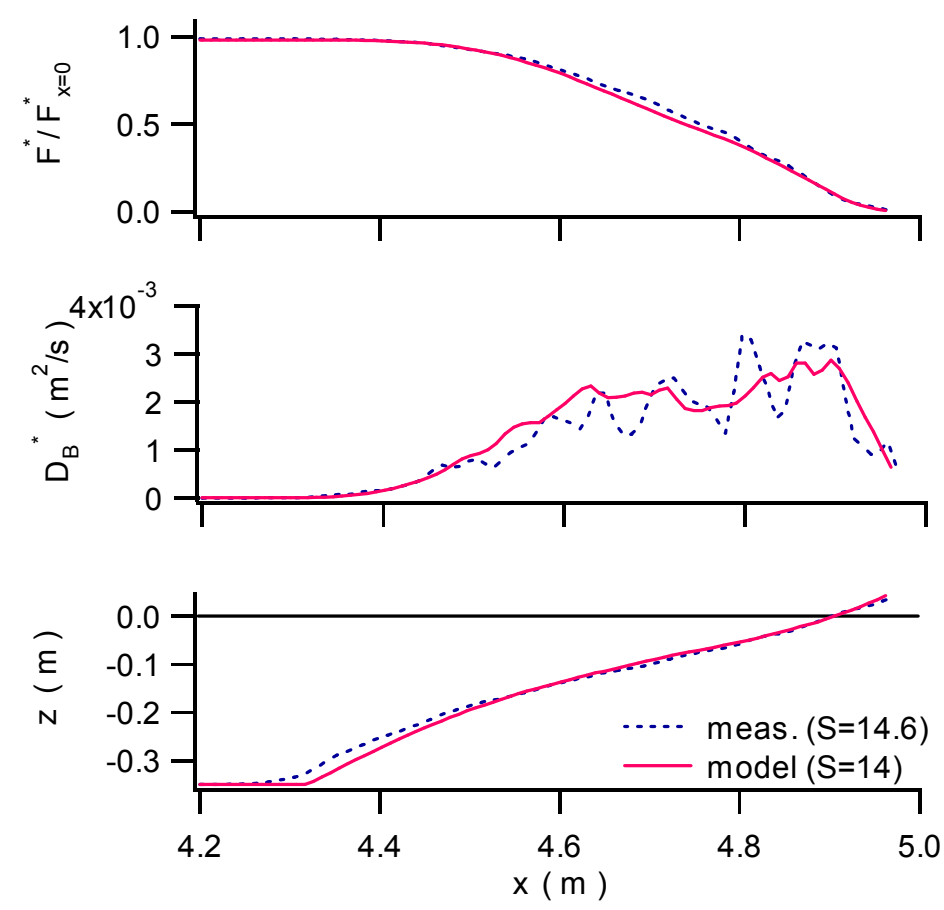

Figure 11. Variations of normalized $F^{*}$ and $D_{B}{ }^{*}$

4. The numerical model predicts $q_{o}$ within about a factor of two; however, the predicted $q_{o}$ shows the reduction tendency as $S$ increases.

\section{ACKNOWLEDGEMENT}

This study was supported by the Grant-in-Aid for Scientific Research (No. 20560479) by Ministry of Education, Culture, Sports, Science and Technology, Japan. The authors thank Akinori Tokioka and Katsuya Imamura for their contribution to the experiments.

\section{REFERENCES}

Battjes, J.A., and M.J.F. Stive. 1985. Calibration and verification of a dissipation model for random breaking waves, Journal of Geophysical Research, 90(C5), 9159-9167.

Kajima, R., T. Sakakiyama, M. Matsuyama, T. Sekimoto and O. Kyoya. 1993. Stability of armor layer of man-made island sea-wall and overtopping due to extremely large irregular waves, Proceedings of 40th Japanese Conference on Coastal Engineering, JSCE, 686-690. (in Japanese)

Kobayashi, N. and F.J. de los Santos. 2007. Irregular wave seepage and overtopping of permeable slopes, Journal of Waterway, Port, Coastal, and Ocean Engineering, Vol. 133, No. 4, ASCE, 245254.

Kobayashi, N., L.E. Meigs, T. Ota and J.A. Melby. 2007. Irregular breaking wave transmission over submerged porous breakwater, Journal of Waterway, Port, Coastal, and Ocean Engineering, Vol. 133, No. 2, ASCE, 104-116.

Ota, T., Y. Matsumi, N. Kobayashi and A. Kimura. 2007. Influence of damage progression on performance of rubble mound breakwater, Coastal Structures 2007, Proceedings of the 5th International Conference, World Scientific, 1806-1817.

Ota, T., Y. Matsumi, T. Hirayama and A. Kimura. 2009. Models for profile change of rubble mound breakwater and revetment and performance evaluation, Annual Journal of Civil Engineering in the Ocean, JSCE, Vol. 25, 175-179. (in Japanese) 